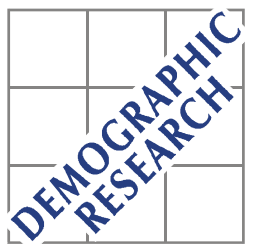

Demographic Research a free, expedited, online journal of peer-reviewed research and commentary in the population sciences published by the Max Planck Institute for Demographic Research Konrad-Zuse Str. 1, D-18057 Rostock · GERMANY www.demographic-research.org

DEMOGRAPHIC RESEARCH

VOLUME 9, ARTICLE 1, PAGES 1-24

PUBLISHED 29 AUGUST 2003

www.demographic-research.org/Volumes/Vol9/1/

DOI: 10.4054/DemRes.2003.9.1

Research Article

\title{
Estimating multistate transition rates from population distributions
}

\author{
Robert Schoen
}

Stefan H. Jonsson

(C) 2003 Max-Planck-Gesellschaft. 


\section{Table of Contents}

1 Introduction 2

2 The iterative proportional fitting method 2

3 The relative state attraction method 4

3.1 The conceptual foundation 4

3.2 Determining the adjustment factors 5

$4 \quad$ Evaluating the RSA method $\quad 7$

4.1 Evaluations of hypothetical changes in rates 7

$\begin{array}{lll}\text { 4.1.1 Models with two living states } & 7\end{array}$

4.1.2 Models with four living states 10

4.2 Evaluations of estimates using actual data for the 13

standard rates

$\begin{array}{lll}5 & \text { A substantive application } & 15\end{array}$

$\begin{array}{lll}6 & \text { Summary and conclusions } & 17\end{array}$

$7 \quad$ Acknowledgements 18

$\begin{array}{ll}\text { Notes } & 19\end{array}$

$\begin{array}{ll}\text { References } & 20\end{array}$

$\begin{array}{ll}\text { Appendix A } & 22\end{array}$

$\begin{array}{ll}\text { Appendix B } & 23\end{array}$ 
Research Article

\title{
Estimating multistate transition rates from population distributions
}

\author{
Robert Schoen ${ }^{1}$ \\ Stefan H. Jonsson ${ }^{2}$
}

\begin{abstract}
The ability to estimate interstate transition rates (or probabilities) from population distributions has many potential applications in demography. Iterative Proportional Fitting (IPF) has been used for such estimation, but lacks a meaningful behavioral foundation. Here a new approach, Relative State Attraction (RSA), is advanced. It assumes that states have a greater (or lesser) ability to attract individuals, and that rates respond accordingly. The RSA estimation procedure is developed and applied to model and actual data where the underlying rates are known. Results show that RSA provides accurate estimates under a wide range of conditions, typically yielding values quite similar to those produced by IPF. Both methods are then applied to U.S. data to provide new estimates of interregional migration between the years 1980 and 1990 .
\end{abstract}

1 Department of Sociology, Pennsylvania State University, University Park, PA 16802, USA.

E-mail: schoen@pop.psu.edu

2 Icelandic Center for Social Research and Analysis and Department of Sociology, Pennsylvania State

University, University Park, PA 16802, USA. E-mail: stefanj@pop.psu.edu 


\section{Introduction}

There are many circumstances where an investigator knows the size and distribution of a multistate population at two fairly close points in time and seeks the transition rates-or the transition probabilities - that characterize the population's behavior over that time interval. For example, census (or survey) figures can provide population counts, at two time points, by marital status, labor force status, or place of residence. It would be very useful if those population counts could be employed to determine the prevailing risks of marriage and divorce, job entry and exit, or interregional migration.

It is well known, however, that knowledge of two population stocks alone is insufficient to uniquely determine the transition rates or probabilities that transform the first population into the second. With $n$ living states, one typically has a set of $n$ equations with $\mathrm{n}^{2}$ unknown rates, hence an infinite number of solutions. The problem of finding optimal solutions has attracted a good deal of attention, but the appropriateness of proposed solutions to demographic analysis is less than clear. Here we review the leading methodological approach to the problem ${ }^{1}$, advance a new, behaviorally based approach, compare both techniques using hypothetical and actual data, and apply them to a problem of substantive interest.

\section{The iterative proportional fitting method}

The principal technique for adjusting the elements of an array to satisfy specified row and column totals is known as iterative proportional fitting (IPF). In different publications, IPF (or an equivalent procedure) has been referred to by a number of names, including the Deming-Stephan procedure, the DSF procedure (after Deming, Stephan, and Furness), bi(or multi-) proportional adjustment, and the RAS method. Bishop, Fienberg and Holland (1975) and Willekens (1982) discuss its development and statistical properties. The earliest application appears to be that of Kruithof (1937), who examined network size needs for different levels of telephone traffic. IPF has been widely used in transportation science to estimate spatial interaction flows, and has been generalized for estimating input-output models.

To describe the procedure, let us consider a non-negative array, $\mathbf{D}$, of $\mathrm{r}$ rows and $\mathrm{c}$ columns, whose ijth element is $d_{i j}$. The $d_{i j}$ can be considered base values, and represent prior knowledge regarding patterns of interaction or movement. Now let $\mathrm{R}_{\mathrm{i}}, \mathrm{i}=1, \mathrm{r}$ be the desired sum of the ith row, and let $\mathrm{C}_{\mathrm{j}}, \mathrm{j}=1, \mathrm{c}$, be the desired sum of the jth column. Work by Kruithof (1937), Deming and Stephan (1940), and Furness (1965) has shown that there is a unique set of row factors, $f_{i}, i=1, r$, and column factors, $g_{j}, j=1, c$, such that there is an array $\mathbf{D}^{*}$, whose ijth element is given by 


$$
\mathrm{d}^{*_{i j}}=\mathrm{d}_{\mathrm{ij}} \mathrm{f}_{\mathrm{i}} \mathrm{g}_{\mathrm{j}}
$$

which has the desired row and column totals. The adjusted elements and the unique factors can be found by (i) successively multiplying each matrix element of a given row by a factor so that those row elements sum to the desired total, and following that procedure for every row, (ii) successively multiplying each (adjusted) element of a given column by a factor so that the column elements sum to the desired total, and following that procedure for every column, and (iii) continuing the process until both row and column totals equal the desired quantities. While the algebraic solution is complex even for matrices with only 2 rows and 2 columns, the IPF procedure has a unique solution and can easily be programmed for matrices of any size.

Iterative proportional fitting has a number of desirable properties. It is equivalent to entropy maximization, where entropy reflects the amount of randomness (or lack of structure) in the data (Willekens 1999). Essentially, the maximum entropy solution finds the pattern of flows achievable in the greatest number of ways (Halli and Rao 1992:190). Entropy maximization is particularly appropriate when the probability model underlying the data is not known, and yields estimates equivalent to those made by maximum likelihood (Batty and Mackie 1972; Bishop, Fienberg and Holland 1975: Ch. 3 and 5). Willekens (1982) showed that IPF is equivalent to estimating an array by log linear modeling, where higher order interactions in the model are ignored. The IPF procedure can be applied to any state space, and readily accommodates "structural zeroes" (i.e. values that must be zero because a transfer between those states is not possible).

Models based on IPF have been applied to several demographic issues. McFarland (1975) used IPF to address the "two-sex problem" of demography, as it could resolve inconsistencies between the number of marriages implied by male and female marriage rates. Estimates of migration arrays have been a major substantive focus (cf. Chilton and Poet 1973; Nair 1985; Philipov 1978; and Willekens 1982). In general, reasonable results have been reported, although migration flows involving small numbers of persons have been estimated poorly in some cases. Previous studies emphasized retrospective data, however, and had only a limited ability to compare their results to accurately known values.

Viewing demographic flows as cross-classified (or contingency table) data allows a number of possible statistical models to be used. Significant statistical modeling of that kind on demographic topics has been done by Willekens (1999), Moffitt (1993), Moffitt and Rendall (1995), and Rogers, Willekens, and Raymer (2001). Here, we focus on the core IPF procedure and its implicit entropy maximization and log linear interpretations. In addition to the transparent nature of those underlying assumptions, the procedure can be applied with a minimum of information beyond the beginning and ending population distributions. 
Despite its strengths, one can question the appropriateness of IPF for demographic analysis. Iterative proportional fitting has no simple demographic interpretation, while demography has always emphasized the order and pattern that characterizes aggregate behavior, and has found numerous behavioral regularities that transcend time and place. What is called for is a behaviorally interpretable procedure, and we now turn to the specification of such an approach.

\section{The relative state attraction method}

\subsection{The conceptual foundation}

When there are $\mathrm{n}$ living states in the model, $\mathrm{n}$ constraints are imposed by the beginning and ending population stocks. As each state provides one constraint, we can think of changes in the extent to which a state "attracts" (or "repels") people. If a state's power to attract people increases, then it is plausible to expect an increase in rates of transfer into the state and a decrease in rates of transfer out. For example, if marriage loses some of its ability to attract, one might expect fewer marriages and more divorces. Similarly, if Region A enjoys economic prosperity and increases its ability to attract people, it should draw inmigrants and discourage outmigrants. While somewhat simplistic, the notion of attraction/repulsion provides a plausible and interpretable basis for adjusting rates of transfer when population distributions and a referent set of rates are available.

To explain the Relative State Attraction (RSA) approach, let $\mathrm{m}_{\mathrm{ij}}(\mathrm{x}, \mathrm{u})$ be some given base (or standard) rate of transfer from state $i$ to state $j$ between ages $x$ and $x+u$. We introduce a set of state-and-age-specific adjustment factors, $\mathrm{k}_{\mathrm{i}}(\mathrm{x}, \mathrm{u})$ to reflect the changes in attraction/repulsion from the base rate conditions, and a set of adjusted rate $m_{i j}{ }^{*}(x, u)$ that satisfy

$$
\mathrm{m}_{\mathrm{ij}} *(\mathrm{x}, \mathrm{u})=\mathrm{m}_{\mathrm{ij}}(\mathrm{x}, \mathrm{u}) \mathrm{k}_{\mathrm{j}}(\mathrm{x}, \mathrm{u}) / \mathrm{k}_{\mathrm{i}}(\mathrm{x}, \mathrm{u})
$$

Each adjusted rate reflects changes in the power of attraction of both its origin and destination states. The rate of transfer from state $i$ to state $\mathrm{j}$ increases as state $\mathrm{j}$ exerts more attraction and decreases as state $i$ exerts more attraction. Through the factors $k_{i}$ and $k_{j}$, the adjusted rates $\mathrm{m}_{\mathrm{ij}}$ * are influenced by behavior in all states.

From the symmetry of the attraction factors for states $i$ and $j$, equation (2) implies

$$
\mathrm{m}_{\mathrm{ij}} *(\mathrm{x}, \mathrm{u}) \mathrm{m}_{\mathrm{ji}} *(\mathrm{x}, \mathrm{u})=\mathrm{m}_{\mathrm{ij}}(\mathrm{x}, \mathrm{u}) \mathrm{m}_{\mathrm{ji}}(\mathrm{x}, \mathrm{u})
$$


or that an increase in one rate is exactly offset by a decrease in the other. The relationship in equation (3) characterizes every pair of living states in the model, and is independent of the number of states being considered. For example, if divorce rates rise, it is reasonable to expect a fall in marriage rates. Similarly, if the rate of migration from A to B increases, it is plausible that the rate of migration from B to A declines. Such patterns have often been observed, although exceptions are not uncommon.

With only $\mathrm{n}$ system constraints on $\mathrm{n}^{2}$ rates, any estimation method must restrict the range of possible behavioral changes. The RSA method does not accurately capture all possible behavioral patterns; no solution can do that. The strength of the RSA method is that it provides is a simple, intuitive, and readily communicable notion that translates the $\mathrm{n}$ available constraints into $\mathrm{n}^{2}$ adjustment factors in a way that yields a reasonable pattern of behavioral change. It is applicable to any state space, and easily accommodates structural zeroes (as zero rates remain zero). In practice it is straightforward to apply. When standard rates and a chronological sequence of population distributions are available, RSA (like IPF) can generate a time trajectory of rates.

Furthermore, RSA opens up new analytical possibilities. Because its underlying assumption is readily interpretable, scenarios can be expressed in terms of changes in state attraction/repulsion. One can start with an initial population and set of rates, and assume that the attraction/repulsion associated with each state changes over time in a given way. For example, it could be assumed that urban areas steadily exert more attraction for those in rural areas, or that the attraction/repulsion (pull/push) factors motivating migration between urban and rural areas vary cyclically over time. Those assumed changes in attraction/repulsion can be used to generate a trajectory of future rates, whose implications can be found by conventional projection techniques. No comparable procedure is possible with IPF because the assumptions underlying IPF cannot readily be expressed in ways with straightforward behavioral implications.

\subsection{Determining the adjustment factors}

The RSA method involves adjusting given behavioral rates, and our procedure uses "flow" equations involving rates that connect the initial and final populations. Let vector $\mathbf{l}(\mathrm{t})$ with ith element $l_{i}(t)$ be the observed initial population vector that provides the number of persons in each state at exact time $t$, let vector $l(t+u)$ with ith element $l_{i}(t+u)$ be the observed population vector at exact time $t+u$, and let $\mathbf{L}(\mathrm{t}, \mathrm{u})$ with ith element $\mathrm{L}_{\mathrm{i}}(\mathrm{x}, \mathrm{u})$ be the vector of person-years lived by state between times $t$ and $t+u$. The $\mathbf{L}$ vectors are considered calculable from the known $\mathbf{I}$ vectors ${ }^{2}$.

Typically, one has a base matrix, $\mathbf{M}$, of rates believed to approximately characterize the observed population. The ijth element of $\mathbf{M}, \mathrm{i} \neq \mathrm{j}$, is $\mathrm{m}_{\mathrm{ij}}$, the transition rate from state $\mathrm{i}$ 
to state $\mathrm{j}$. The ith diagonal element of $\mathbf{M}$ can be written as $\varphi_{\mathrm{i}}-\mu_{\mathrm{i}}-\Sigma_{\mathrm{j}} \mathrm{m}_{\mathrm{ij}}$, where the summation index $j$ ranges over all living states other than $i ; \varphi_{i}$ is the fertility rate in state $i$; and $\mu_{\mathrm{i}}$ is the death (or "loss") rate in state $\mathrm{i}$. As defined, $\mathbf{M}$ can reflect the demographic behavior of any multistate population (cf. Schoen 1988; Ch. 4).

We require that the matrix $\mathbf{M} *(t, u)$ of adjusted rates satisfy the interstate flow equation

$$
\mathbf{I}(\mathrm{t}+\mathrm{u})=\mathbf{I}(\mathrm{t})+\mathbf{M}^{*(\mathrm{~T})}(\mathrm{t}, \mathrm{u}) \mathbf{L}(\mathrm{t}, \mathrm{u})
$$

where the superscript (T) indicates the matrix transpose. The ijth element of $\mathbf{M} *(t, u), i \neq j$, is $\mathrm{m}_{\mathrm{ij}} *(\mathrm{t}, \mathrm{u})=\mathrm{m}_{\mathrm{ij}}(\mathrm{t}, \mathrm{u}) \mathrm{k}_{\mathrm{j}}(\mathrm{t}, \mathrm{u}) / \mathrm{k}_{\mathrm{i}}(\mathrm{t}, \mathrm{u})$. The ith diagonal element of $\mathbf{M} *(\mathrm{t}, \mathrm{u})$ is $\mathrm{m}_{\mathrm{ii}} *(\mathrm{t}, \mathrm{u})=\varphi_{\mathrm{i}}$ $\mathrm{k}_{\mathrm{i}}(\mathrm{t}, \mathrm{u})-\mu_{\mathrm{i}} / \mathrm{k}_{\mathrm{i}}(\mathrm{t}, \mathrm{u})-\Sigma_{\mathrm{j}} \mathrm{m}_{\mathrm{ij}}{ }^{*}(\mathrm{t}, \mathrm{u})$. In this formulation, a state's mortality and fertility are assumed to respond only to changes in its own power of attraction, with greater attraction raising fertility and lowering mortality. Thus the state i fertility rate is multiplied by the adjustment factor for state $\mathrm{i}$ and the state i mortality rate is divided by that factor. In effect, the "dead" state and the "preborn" state are assumed to have constant adjustment factors equal to 1. That both avoids the need for introducing additional unknowns and is consistent with the idea that a state's greater power of attraction increases entrants and decreases exits. ${ }^{3}$ Substantively the assumption is plausible, though it does not always hold.

Solving equation (4) means using its $n$ scalar equations to find the $n$ adjustment factors $\mathrm{k}_{\mathrm{i}}(\mathrm{t}, \mathrm{u})$ \{or the ratios $\left.\mathrm{k}_{\mathrm{i}}(\mathrm{t}, \mathrm{u}) / \mathrm{k}_{\mathrm{j}}(\mathrm{t}, \mathrm{u})\right\}$. Algebraically, those equations are nonlinear and give rise to complicated expressions for the $\mathrm{k}_{\mathrm{i}}$. Even the general two living state model yields a complicated cubic solution. To indicate the nature of the mechanisms involved, Appendix A gives the quadratic solutions for two restricted $n=2$ models. Moreover, Appendix A.2 shows that there is a unique realistic solution for a two state model with no mortality or fertility (or for a two state model where mortality and fertility are determined by the procedure described in note 3 ).

Numerically, the solution can readily be found using a mathematical program such as Maple. Numerous Maple and Octave calculations involving models with 2, 3, and 4 living states have been made, and have always produced one and only one solution with demographically realistic values (i.e. all $k_{\mathrm{i}}>0$ ). When a model includes mortality or fertility, a numerical solution for each $\mathrm{k}_{\mathrm{i}}$ can be found. When the model includes neither fertility nor mortality, the $\mathrm{k}_{\mathrm{i}}$ are only determined up to a multiplicative constant, and the unique realistic solution is best expressed in terms of $k_{i} / k_{j}$ ratios. However, a general proof that there must be a unique, demographically realistic solution is not available, and the existence of such a solution may depend on the choice of standard matrix $\mathbf{M}$. 


\section{Evaluating the RSA method}

We examine the RSA method, and compare it with the IPF approach, in two ways. First we consider hypothetical multistate life table contexts where observed age-specific rate schedules are shifted proportionately at all ages. Second, we estimate transfer rates using real data when the actual transfer rates are known. RSA is a new and untested method, but these comparisons are also the first time that the IPF method has been systematically evaluated with respect to known rates in a demographic application.

\subsection{Evaluations of hypothetical changes in rates}

The venerable demographic technique of indirect standardization is based on the idea that there is an underlying regularity in the pattern of demographic behavior over age. In that spirit, we produce a simulated set of age curves of rates by shifting the observed rates proportionately, up or down, at all ages. We then examine how the RSA and IPF methods respond, age by age. The imposed proportional pattern of change is quite distinct from the assumptions underlying both estimation approaches.

\subsubsection{Models with two living states}

Table 1 and Figure 1 are based on a two-living state married/unmarried model calculated from data for the cohort of Swedish females born 1930-34 (see Schoen 1988, 92-93). We focus on the rates of transfer from Unmarried (U) to Married (M) and from M to U. A number of standard rates are used. They are the actual rates multiplied by an arbitrary modification factor: $\mathrm{F}_{\mathrm{UM}}$ for transfers from Unmarried to Married, and $\mathrm{F}_{\mathrm{MU}}$ for transfers from Married to Unmarried. To reflect a considerable degree of change, the factors chosen were .7, .8, and .9, along with their (approximate) reciprocals 1.4, 1.25, and 1.1 and base value 1.0. Thus the "correct" rates for either transition could be as much as $40 \%$ higher or $30 \%$ lower than the "standard" used. Because equation (3) indicates that RSA is based on the assumption that the product of the two interstate transfer rates remains constant, Table 1 includes a column showing the product of $\mathrm{F}_{\mathrm{UM}}$ and $\mathrm{F}_{\mathrm{MU}}$. The life table population values remain fixed. 
A. M-U factor .7 U-M factor .7

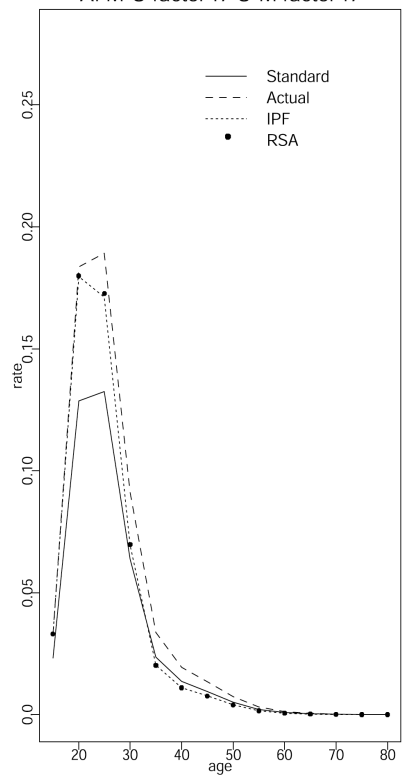

B. M-U factor 1.4 U-M factor .7

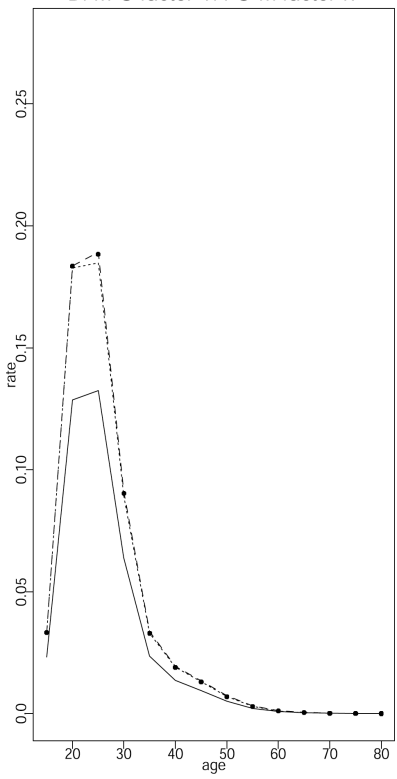

C. M-U factor 1.4 U-M factor 1.4

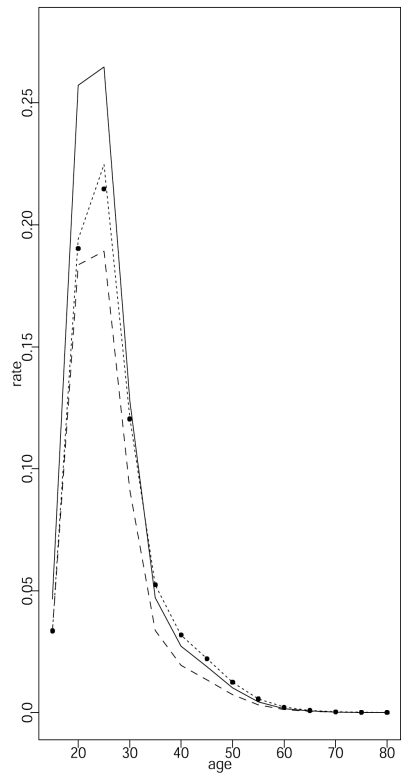

Figure 1: Actual, estimated, and standardized marriage rates from two-living state (married/unmarried) model based on rates for Sweden, female cohort born 1930-1934

Figure 1 shows the age-specific marriage rates (i.e. the rates of transfer from $U$ to $M$ ) in three cases: when both $\mathrm{F}_{\mathrm{UM}}$ and $\mathrm{F}_{\mathrm{MU}}$ are .70 , when $\mathrm{F}_{\mathrm{UM}}=.70$ and $\mathrm{F}_{\mathrm{MU}}=1.40$ (and their product is .98), and when both factors are 1.40. When the product of the factors was close to one (Panel B), both RSA and IPF tracked the actual rates very closely. The discrepancies were considerably greater when the product of the factors departed substantially from 1, though again the RSA and IPF estimates were quite close to each other and yielded a reasonable pattern over age. 
Table 1: $\quad$ Mean proportional errors of RSA and IPF rate estimates in the context of a two-state (married/unmarried) life table model based on the experience of Swedish females born 1930-34

\begin{tabular}{|c|c|c|c|c|c|c|c|c|}
\hline \multirow{3}{*}{$\begin{array}{c}\text { Factor } \\
\underline{\mathrm{U}-\mathrm{M}}\end{array}$} & \multirow{3}{*}{$\begin{array}{c}\text { Factor } \\
\underline{M-U} \\
\end{array}$} & \multirow{3}{*}{$\begin{array}{c}\text { Product } \\
(\mathrm{U}-\mathrm{M})^{\star}(\mathrm{M}-\mathrm{U}) \\
\end{array}$} & \multicolumn{3}{|c|}{ Unmarried to Married } & \multicolumn{3}{|c|}{ Married to Unmarried } \\
\hline & & & \multicolumn{2}{|c|}{ MPE from } & \multirow{2}{*}{$\frac{\text { MPE Ratio }}{\underline{\text { IPF/RSA }}}$} & \multicolumn{2}{|c|}{ MPE from } & \multirow{2}{*}{$\begin{array}{l}\text { MPE Ratio } \\
\text { IPF/RSA }\end{array}$} \\
\hline & & & RSA & $\underline{\text { IPF }}$ & & RSA & $\underline{\text { IPF }}$ & \\
\hline .70 & .70 & .490 & 0.375 & 0.383 & 1.02 & 0.181 & 0.188 & 1.04 \\
\hline .70 & .80 & .560 & 0.324 & 0.331 & 1.02 & 0.146 & 0.154 & 1.06 \\
\hline .70 & .90 & .630 & 0.275 & 0.280 & 1.02 & 0.113 & 0.123 & 1.09 \\
\hline .70 & 1.00 & .700 & 0.228 & 0.229 & 1.01 & 0.082 & 0.093 & 1.14 \\
\hline .70 & 1.10 & .770 & 0.181 & 0.178 & .99 & 0.067 & 0.080 & 1.19 \\
\hline .70 & 1.25 & .875 & 0.113 & 0.101 & .90 & 0.048 & 0.063 & 1.31 \\
\hline .70 & 1.40 & .980 & 0.046 & 0.038 & .82 & 0.036 & 0.053 & 1.48 \\
\hline .80 & .80 & .640 & 0.259 & 0.266 & 1.03 & 0.122 & 0.129 & 1.05 \\
\hline .80 & .90 & .720 & 0.204 & 0.209 & 1.02 & 0.087 & 0.095 & 1.09 \\
\hline .80 & 1.00 & .800 & 0.150 & 0.152 & 1.01 & 0.054 & 0.063 & 1.18 \\
\hline .80 & 1.10 & .880 & 0.098 & 0.095 & .96 & 0.037 & 0.048 & 1.29 \\
\hline .80 & 1.25 & 1.000 & 0.022 & 0.017 & .78 & 0.023 & 0.035 & 1.54 \\
\hline .80 & 1.40 & 1.120 & 0.053 & 0.080 & 1.53 & 0.065 & 0.049 & .76 \\
\hline .90 & .90 & .810 & 0.134 & 0.138 & 1.04 & 0.062 & 0.066 & 1.07 \\
\hline .90 & 1.00 & .900 & 0.075 & 0.075 & 1.01 & 0.026 & 0.032 & 1.22 \\
\hline .90 & 1.10 & .990 & 0.017 & 0.013 & .77 & 0.011 & 0.018 & 1.64 \\
\hline .90 & 1.25 & 1.125 & 0.067 & 0.083 & 1.24 & 0.055 & 0.045 & .83 \\
\hline .90 & 1.40 & 1.260 & 0.149 & 0.181 & 1.21 & 0.100 & 0.088 & .88 \\
\hline 1.00 & 1.00 & 1.000 & 0.000 & 0.000 & -- & 0.000 & 0.000 & -- \\
\hline 1.00 & 1.10 & 1.100 & 0.063 & 0.069 & 1.10 & 0.035 & 0.034 & .97 \\
\hline 1.00 & 1.25 & 1.250 & 0.155 & 0.174 & 1.12 & 0.086 & 0.083 & .97 \\
\hline 1.00 & 1.40 & 1.400 & 0.245 & 0.281 & 1.15 & 0.133 & 0.128 & .96 \\
\hline 1.10 & 1.10 & 1.210 & 0.142 & 0.149 & 1.05 & 0.063 & 0.071 & 1.12 \\
\hline 1.10 & 1.25 & 1.375 & 0.241 & 0.263 & 1.09 & 0.116 & 0.122 & 1.06 \\
\hline 1.10 & 1.40 & 1.540 & 0.338 & 0.379 & 1.12 & 0.166 & 0.171 & 1.03 \\
\hline 1.25 & 1.25 & 1.563 & 0.368 & 0.395 & 1.07 & 0.160 & 0.187 & 1.17 \\
\hline 1.25 & 1.40 & 1.750 & 0.476 & 0.525 & 1.10 & 0.213 & 0.241 & 1.13 \\
\hline 1.40 & 1.40 & 1.960 & 0.611 & 0.669 & 1.10 & 0.259 & 0.322 & 1.24 \\
\hline
\end{tabular}


Table 1 shows the overall errors found when every value of $\mathrm{F}_{\mathrm{UM}}$ was combined with every equal or higher value of $\mathrm{F}_{\mathrm{MU}}$. The measure of accuracy used is the Mean Proportional Error (MPE) where the proportional error is

$$
\mathrm{PE}=(\text { Actual }- \text { Estimated }) / \text { Actual }
$$

Since the principal marriage ages are approximately 15-39, the MPE values shown in Table 1 reflect the average of the absolute values of the proportional errors for those ages. The IPF/RSA ratio of MPE values is also shown, with a ratio over 1 indicating that the IPF method has a larger error, and a ratio under 1 indicating that the RSA method has a larger error.

Table 1 shows that RSA and IPF yielded fairly similar error levels, though RSA usually did a bit better. When the product of $\mathrm{F}_{\mathrm{UM}}$ and $\mathrm{F}_{\mathrm{MU}}$ was close to one, the MPE was small, e.g less than $2 \%$ when $\mathrm{F}_{\mathrm{UM}}$ was .90 and $\mathrm{F}_{\mathrm{MU}}$ was 1.10 . At the extremes, shown in panels A and C of Figure 1, the MPE was from near $40 \%$ to over $60 \%$. As is true for indirect standardization, the results are thus standard dependent. Standards that yield offsetting changes in the rates produce good results for both methods, though all of the standards used led to reasonable marriage patterns over age. It is not surprising that the RSA estimates go increasingly off as the underlying state attraction assumption increasingly departs from the actual circumstances. What is surprising is that the IPF estimates go off in very much the same way, even though its underlying assumptions are quite different.

\subsubsection{Models with four living states}

Let us now consider a marital status model with four states: Never Married (s), Currently Married (m), Widowed (w), and Divorced (v). Table 2 and Figure 2 show values based on observed data for United States Females, 1995 (cf. Schoen and Standish 2001). The adjustment factors again range from .7 to 1.4 , with $\mathrm{F}_{\mathrm{UM}}$ reflecting the adjustment made to all marriage rates, and $\mathrm{F}_{\mathrm{MV}}$ reflecting the adjustment to the divorce rate. The other rates in the model are not changed, and life table values are again used for the initial and ending populations. Our comparison focuses on the rates of transfer from Never Married to Married $\left(\mathrm{m}_{\mathrm{sm}}\right)$, Married to Divorced $\left(\mathrm{m}_{\mathrm{mv}}\right)$, and Divorced to Married $\left(\mathrm{m}_{\mathrm{vm}}\right)$, and MPEs are based on ages 18 through $45-49$. 
A. M-V factor .7 U-M factor .7
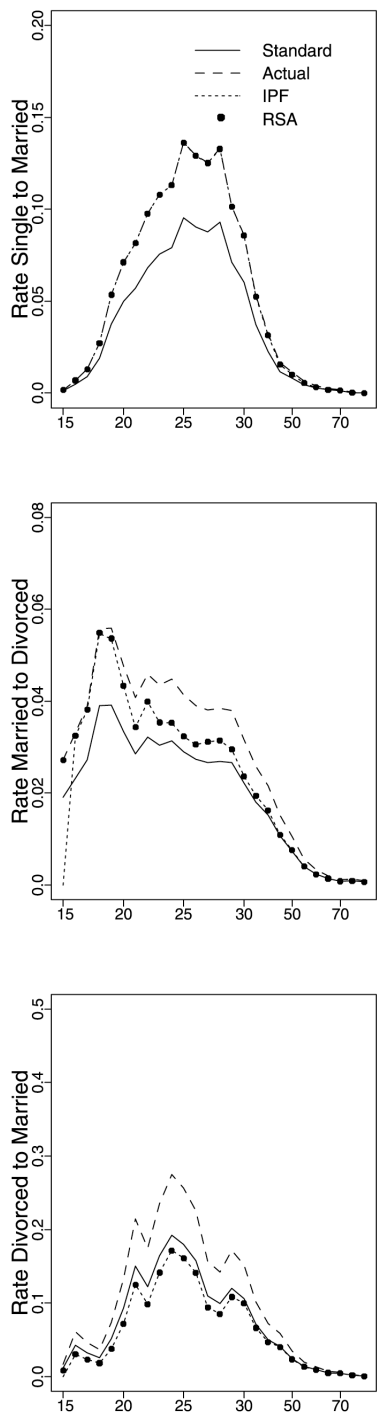

B. M-V factor $1.4 \mathrm{U}-\mathrm{M}$ factor .7
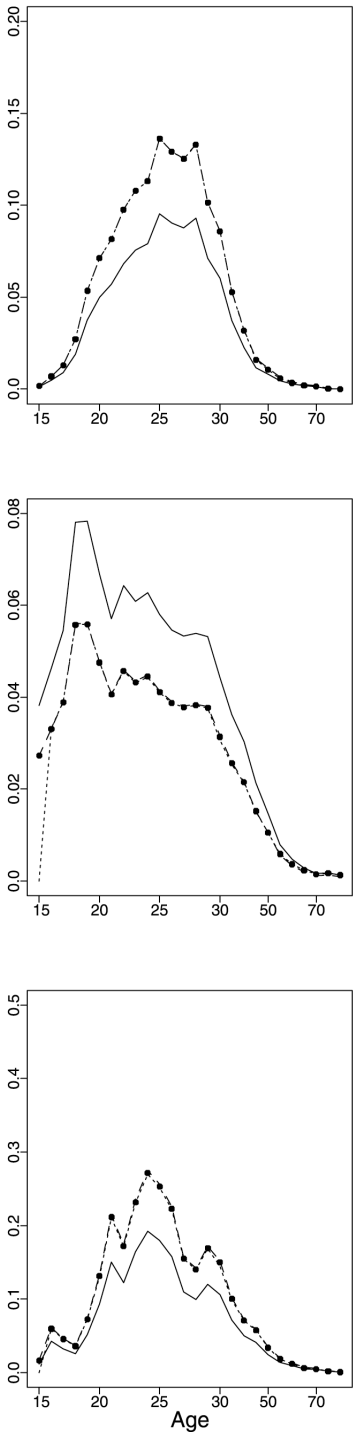

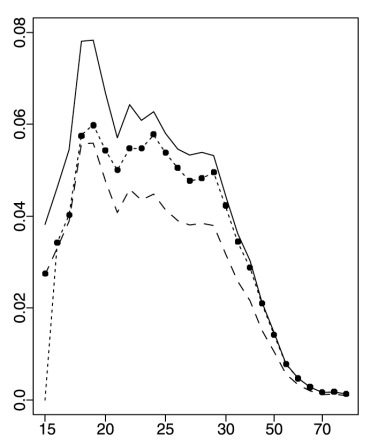

C. M-V factor $1.4 \mathrm{U}-\mathrm{M}$ factor 1.4
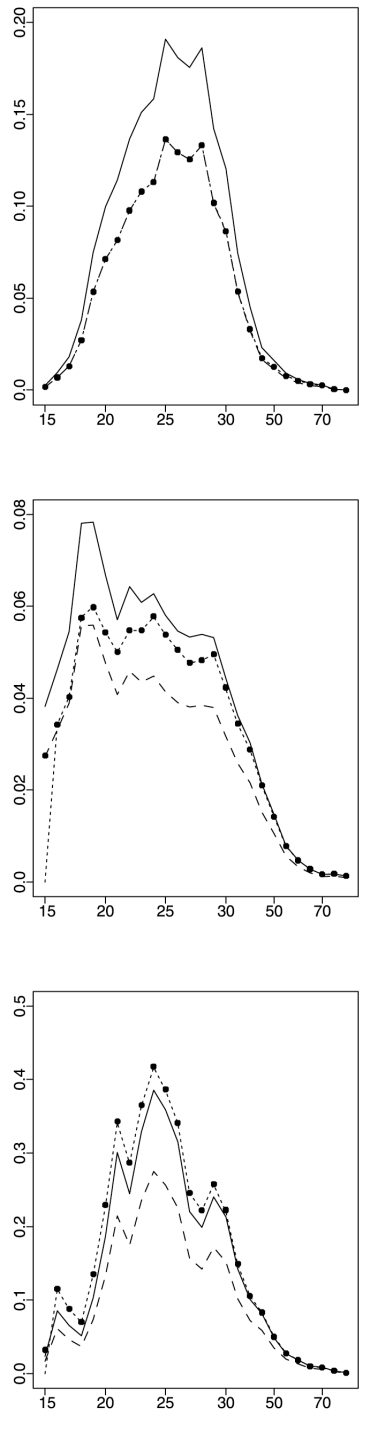

Figure 2: $\quad$ Actual, estimated, and standardized marriage rates from four-living state model based on rates for USA females in 1995 
Table 2: $\quad$ Mean Proportional Errors of RSA and IPF Rate Estimates in the Context of a Four State Marital Status Life Table Based on the Experience of United States Females in the Year 1995.

\begin{tabular}{|c|c|c|c|c|c|c|c|c|c|c|c|}
\hline \multirow{3}{*}{$\begin{array}{l}\text { All Marriage } \\
\text { Rates } \\
\text { Factor } \\
\text { U-M }\end{array}$} & \multirow{3}{*}{$\begin{array}{l}\text { Divorce } \\
\text { Rate } \\
\text { Factor } \\
\underline{\mathrm{M}-\mathrm{V}}\end{array}$} & \multirow{3}{*}{$\begin{array}{c}\text { Product } \\
(\mathrm{U}-\mathrm{M})^{\star}(\mathrm{M}-\mathrm{V}) \\
\end{array}$} & \multicolumn{3}{|c|}{ Single to Married } & \multicolumn{3}{|c|}{ Married to Divorced } & \multicolumn{3}{|c|}{ Divorced to Married } \\
\hline & & & \multicolumn{2}{|c|}{ MPE from } & \multirow{2}{*}{$\begin{array}{c}\text { MPE } \\
\underline{\text { Ratio }} \\
\text { IPF/RSA } \\
\end{array}$} & \multicolumn{2}{|c|}{ MPE from } & \multirow{2}{*}{$\begin{array}{c}\text { MPE } \\
\text { Ratio } \\
\underline{\text { IPF/RSA }} \\
\end{array}$} & \multicolumn{2}{|c|}{ MPE from } & \multirow{2}{*}{$\begin{array}{c}\text { MPE } \\
\text { Ratio } \\
\text { IPF/RSA } \\
\end{array}$} \\
\hline & & & $\underline{\text { RSA }}$ & $\underline{\mathrm{IPF}}$ & & $\underline{\mathrm{RSA}}$ & $\underline{\mathrm{IPF}}$ & & RSA & $\underline{\mathrm{IPF}}$ & \\
\hline .70 & .70 & .490 & 0.007 & 0.007 & 1.01 & 0.181 & 0.181 & 1.00 & 0.397 & 0.396 & 1.00 \\
\hline .70 & .80 & .560 & 0.007 & 0.007 & 1.00 & 0.152 & 0.153 & 1.00 & 0.336 & 0.336 & 1.00 \\
\hline .70 & .90 & .630 & 0.006 & 0.006 & .99 & 0.125 & 0.126 & 1.00 & 0.278 & 0.278 & 1.00 \\
\hline .70 & 1.00 & .700 & 0.006 & 0.006 & .97 & 0.099 & 0.100 & 1.01 & 0.221 & 0.223 & 1.01 \\
\hline .70 & 1.10 & .770 & 0.005 & 0.005 & .95 & 0.074 & 0.076 & 1.02 & 0.167 & 0.170 & 1.02 \\
\hline .70 & 1.25 & .875 & 0.005 & 0.005 & .92 & 0.039 & 0.041 & 1.05 & 0.089 & 0.094 & 1.05 \\
\hline .70 & 1.40 & .980 & 0.005 & 0.004 & .88 & 0.005 & 0.009 & 1.66 & 0.015 & 0.021 & 1.46 \\
\hline .80 & .80 & .640 & 0.004 & 0.004 & 1.01 & 0.122 & 0.121 & 1.00 & 0.269 & 0.268 & 1.00 \\
\hline .80 & .90 & .720 & 0.004 & 0.004 & .99 & 0.092 & 0.093 & 1.00 & 0.206 & 0.206 & 1.00 \\
\hline .80 & 1.00 & .800 & 0.004 & 0.004 & .97 & 0.064 & 0.065 & 1.01 & 0.144 & 0.146 & 1.01 \\
\hline .80 & 1.10 & .880 & 0.003 & 0.003 & .94 & 0.038 & 0.039 & 1.04 & 0.085 & 0.088 & 1.03 \\
\hline .80 & 1.25 & 1.000 & 0.003 & 0.002 & .88 & 0.001 & 0.003 & 5.30 & 0.001 & 0.006 & 11.16 \\
\hline .80 & 1.40 & 1.120 & 0.002 & 0.002 & .86 & 0.037 & 0.033 & .91 & 0.081 & 0.073 & .91 \\
\hline .90 & .90 & .810 & 0.002 & 0.002 & 1.02 & 0.061 & 0.061 & 1.00 & 0.137 & 0.136 & 1.00 \\
\hline .90 & 1.00 & .900 & 0.002 & 0.002 & .97 & 0.031 & 0.032 & 1.02 & 0.071 & 0.072 & 1.01 \\
\hline .90 & 1.10 & .990 & 0.001 & 0.001 & .90 & 0.003 & 0.004 & 1.47 & 0.007 & 0.010 & 1.35 \\
\hline .90 & 1.25 & 1.125 & 0.001 & 0.001 & .84 & 0.038 & 0.035 & .94 & 0.084 & 0.079 & .94 \\
\hline .90 & 1.40 & 1.260 & 0.001 & 0.001 & .96 & 0.076 & 0.073 & .95 & 0.172 & 0.163 & .95 \\
\hline 1.00 & 1.00 & 1.000 & 0.000 & 0.000 & -- & 0.000 & 0.000 & -- & 0.000 & 0.000 & -- \\
\hline 1.00 & 1.10 & 1.100 & 0.000 & 0.000 & 1.31 & 0.030 & 0.029 & .97 & 0.068 & 0.066 & .97 \\
\hline 1.00 & 1.25 & 1.250 & 0.001 & 0.001 & 1.35 & 0.073 & 0.071 & .97 & 0.165 & 0.160 & .97 \\
\hline 1.00 & 1.40 & 1.400 & 0.001 & 0.002 & 1.39 & 0.114 & 0.110 & .97 & 0.259 & 0.250 & .97 \\
\hline 1.10 & 1.10 & 1.210 & 0.002 & 0.002 & 1.02 & 0.062 & 0.062 & 1.00 & 0.140 & 0.139 & .99 \\
\hline 1.10 & 1.25 & 1.375 & 0.002 & 0.002 & 1.09 & 0.107 & 0.105 & .98 & 0.244 & 0.239 & .98 \\
\hline 1.10 & 1.40 & 1.540 & 0.003 & 0.003 & 1.14 & 0.150 & 0.146 & .97 & 0.342 & 0.334 & .97 \\
\hline 1.25 & 1.25 & 1.563 & 0.004 & 0.004 & 1.02 & 0.156 & 0.155 & .99 & 0.356 & 0.353 & .99 \\
\hline 1.25 & 1.40 & 1.750 & 0.004 & 0.005 & 1.06 & 0.202 & 0.198 & .98 & 0.463 & 0.455 & .98 \\
\hline 1.40 & 1.40 & 1.960 & 0.006 & 0.006 & 1.03 & 0.250 & 0.248 & .99 & 0.578 & 0.571 & .99 \\
\hline
\end{tabular}


Figure 2 shows the three rates of interest when the factors $\mathrm{F}_{\mathrm{UM}}$ and $\mathrm{F}_{\mathrm{MV}}$ are $(.7, .7),(.7$, $1.4)$, and $(1.4,1.4)$. Once again, when the product of the factors is close to one (as in panel B), both methods closely reproduce the actual rates. Estimates of $\mathrm{m}_{\mathrm{sm}}$ are consistently good (under 1\%) for both methods, because the Never Married state has no entrants, and thus there are no complications from a transfer rate from Presently Married to Never Married. Estimates of $\mathrm{m}_{\mathrm{mv}}$ and $\mathrm{m}_{\mathrm{vm}}$ are increasingly in error as the product of the factors departs from one, though again the two methods generate similar estimates and produce a reasonable pattern over age. When the factors are both below one or both above one (Panels $\mathrm{A}$ and $\mathrm{C}$ of Figure 2), the $\mathrm{m}_{\mathrm{mv}}$ estimates are between the standard and actual values, while the $\mathrm{m}_{\mathrm{vm}}$ estimates are a bit further away from the actual than the standard. Nonetheless, for most factor combinations, the error level is not bad considering the limited input data.

\subsection{Evaluations of estimates using actual data for the standard rates}

Table 3 shows standard, actual, and RSA and IPF estimates of $\mathrm{m}_{\mathrm{sm}}, \mathrm{m}_{\mathrm{mv}}$, and $\mathrm{m}_{\mathrm{vm}}$ for United States Females, 1995, when the standard is based on observed values for United States Females, 1988. While not far apart in time, the marriage and divorce rates of those two years showed quite different patterns. In 1995, marriage, divorce, and remarriage rates were much lower at young ages but somewhat higher at older ages than they were in 1988 . Thus the 1988 standard implies reinforcing, not offsetting, changes in the rates, and affords a demanding test of the RSA approach.

Both methods again produced similar estimates. While the first marriage estimates were again quite close, the remarriage and divorce rate estimates were somewhat off. The fall in first marriage and divorce rates at the young ages, combined with the large drop in rates of remarriage from divorce, produced large errors in $\mathrm{m}_{\mathrm{vm}}$ at ages below 25 . Nonetheless, Table 4 shows that those errors generally did not produce poor estimates of the major summary measures. For example, the actual 1995 probability that a marriage would end in divorce was .425, while the RSA estimate was .415 and the IPF estimate was .419. The RSA and IPF methods are thus reasonably robust to the choice of standard in terms of producing useful estimates of overall behavior. Again, what is striking is that the IPF estimates were less accurate and had errors paralleling the RSA estimates when the assumptions underlying the RSA method were violated. 
Table 3: $\quad$ Standard (year 1988), actual (year 1995), and estimated rates for U.S. females, using the relative state attraction (RSA) and iterative proportional fitting (IPF) approaches

\begin{tabular}{lllllllllllll}
\hline \multicolumn{1}{c}{ Single to Married } & \multicolumn{1}{c}{ Married to Divorce } & \multicolumn{4}{c}{ Divorced to Married } \\
Age & Standard & Actual & RSA & IPF & Standard & Actual & RSA & IPF & Standard & Actual & RSA & IPF \\
\hline 18 & .05701 & .02722 & .02727 & .02728 & .10390 & .05579 & .08814 & .08423 & .57823 & .03682 & .78180 & .68688 \\
19 & .07184 & .05353 & .05361 & .05368 & .12581 & .05593 & .09958 & .09307 & .54149 & .07387 & .81975 & .69553 \\
20 & .10124 & .07127 & .07135 & .07134 & .06814 & .04766 & .07076 & .07122 & .50253 & .13350 & .47543 & .48313 \\
21 & .12319 & .08164 & .08173 & .08174 & .07107 & .04080 & .06704 & .06582 & .52848 & .21473 & .58260 & .56459 \\
22 & .13446 & .09772 & .09780 & .09779 & .06563 & .04588 & .06991 & .07099 & .52997 & .17490 & .48020 & .49464 \\
23 & .12419 & .10803 & .10805 & .10803 & .06369 & .04347 & .06635 & .06715 & .53343 & .23492 & .49972 & .50932 \\
24 & .10574 & .11321 & .11322 & .11321 & .05863 & .04478 & .06093 & .06155 & .47975 & .27526 & .45219 & .45930 \\
25 & .15988 & .13640 & .13640 & .13640 & .04692 & .04141 & .04434 & .04406 & .26695 & .25661 & .28659 & .28363 \\
26 & .14562 & .12927 & .12912 & .12912 & .04302 & .03899 & .04285 & .04283 & .26159 & .22564 & .26278 & .26268 \\
27 & .12802 & .12540 & .12528 & .12526 & .03804 & .03804 & .04325 & .04367 & .23829 & .15729 & .20423 & .20826 \\
28 & .10573 & .13309 & .13276 & .13273 & .03567 & .03845 & .04415 & .04486 & .24390 & .14234 & .18895 & .19497 \\
29 & .09245 & .10172 & .10171 & .10169 & .03300 & .03798 & .03762 & .03795 & .19695 & .17164 & .16910 & .17165 \\
30 & .06657 & .08609 & .08287 & .08279 & .02670 & .03160 & .02788 & .02843 & .13770 & .15208 & .12698 & .13100 \\
35 & .04198 & .05313 & .05218 & .05170 & .02230 & .02582 & .02300 & .02323 & .09030 & .10170 & .08599 & .08702 \\
40 & .02084 & .03241 & .03172 & .03076 & .01900 & .02161 & .01965 & .01989 & .06690 & .07196 & .06338 & .06407 \\
45 & .01186 & .01657 & .01643 & .01556 & .01300 & .01523 & .01257 & .01271 & .04640 & .05856 & .04723 & .04746 \\
50 & .00732 & .01148 & .01081 & .00942 & .00780 & .01041 & .00835 & .00864 & .03030 & .03479 & .02720 & .02739 \\
\hline
\end{tabular}

Table 4: $\quad$ Selected summary measures from actual 1988, actual 1995, and estimated 1995 female marital status life tables for the United States.

\begin{tabular}{|c|c|c|c|c|}
\hline \multirow[t]{2}{*}{ Measure } & \multicolumn{2}{|c|}{ Actual } & \multirow{2}{*}{$\begin{array}{c}\text { RSA Estimated } \\
1995\end{array}$} & \multirow{2}{*}{$\begin{array}{c}\text { IPF Estimated } \\
1995\end{array}$} \\
\hline & 1988 & 1995 & & \\
\hline \multicolumn{5}{|l|}{ 1. PROPORTION EVER MARRYING OF THOSE } \\
\hline SURVIVING TO AGE 15 & .879 & .887 & .886 & .884 \\
\hline 2. MEAN AGE AT FIRST MARRIAGE & 25.1 & 26.6 & 26.6 & 26.6 \\
\hline \multicolumn{5}{|l|}{ 3. NUMBER OF MARRIAGES PER PERSON } \\
\hline MARRYING & 1.51 & 1.46 & 1.45 & 1.46 \\
\hline \multicolumn{5}{|l|}{ 4. PROPORTION OF MARRIAGES ENDING IN } \\
\hline DIVORCE & .432 & .425 & .415 & .419 \\
\hline 5. MEAN AGE AT DIVORCE & 34.4 & 37.3 & 35.5 & 35.6 \\
\hline 6. AVERAGE DURATION OF A MARRIAGE & 24.8 & 25.7 & 25.8 & 25.8 \\
\hline \multicolumn{5}{|l|}{ 7. REMARRIAGES OF WIDOWED } \\
\hline PERSONS/WIDOWHOODS & .063 & .048 & .057 & .056 \\
\hline \multicolumn{5}{|l|}{ 8. REMARRIAGES OF DIVORCED } \\
\hline PERSONS/DIVORCES & .723 & .687 & .695 & .695 \\
\hline 9. MEAN AGE AT REMARRIAGE FROM DIVORCED & 36.0 & 39.7 & 37.8 & 37.8 \\
\hline
\end{tabular}




\section{A substantive application}

To show how the RSA method can be applied to produce useful results, we estimate rates of interregional migration in the United States for the period 1980-1990. Such rates are not known at present, although rates for the period 1985-90 have been calculated from a retrospective question in the 1990 Census that asked place of residence in 1985. Appendix B describes how 1980 and 1990 Census figures, and life table values for the 1989-91 period, were used to calculate multiregional life tables for the U.S., 1980-90. Four regions were recognized: North-east, Mid-west, South, and West.

Figure 3 compares RSA estimated age-specific female rates into and out of the Midwest for 1980-90 with analogous rates for 1985-90. There are clear differences between the two, with the entire decade having lower rates of migration into the Mid-west from every other region, and higher rates of migration out of the Mid-west to every other region. That pattern is found in all age groups. Expressing that pattern in terms of RSA assumptions, the Mid-west region exerted more attraction during 1985-90 than it did over the 1980-90 decade.

Table 5 presents selected measures from female multiregional life tables based on the 1985-90 period and comparable figures for the 1980-90 period from separate tables calculated by RSA and by IPF. While the total amount of movement is very much the same in all 3 models (.676 vs. .674 moves per person), there is a definite difference in interregional migration patterns. The RSA and IPF values are again very close. Figure 3 would essentially be unchanged if IPF instead of RSA values were used. Both estimates for the 1980-90 decade yield substantially more net migration out of the Mid-west than does the table for 1985-90. For the whole decade, there was less net migration out of the North-east and more net migration into the South. The West region gained appreciably from net migration over the decade, but lost some population to net migration during the 1985-90 period. Even in this abbreviated presentation, it is evident that the RSA (or the IPF) estimated decade rates provide a new perspective, both qualitatively and quantitatively. To understand U.S. interregional migration in the 1980's, one should extend the analysis beyond the previously available rates, which only covered the second half of the decade. 
Demographic Research - Volume 9, Article 1
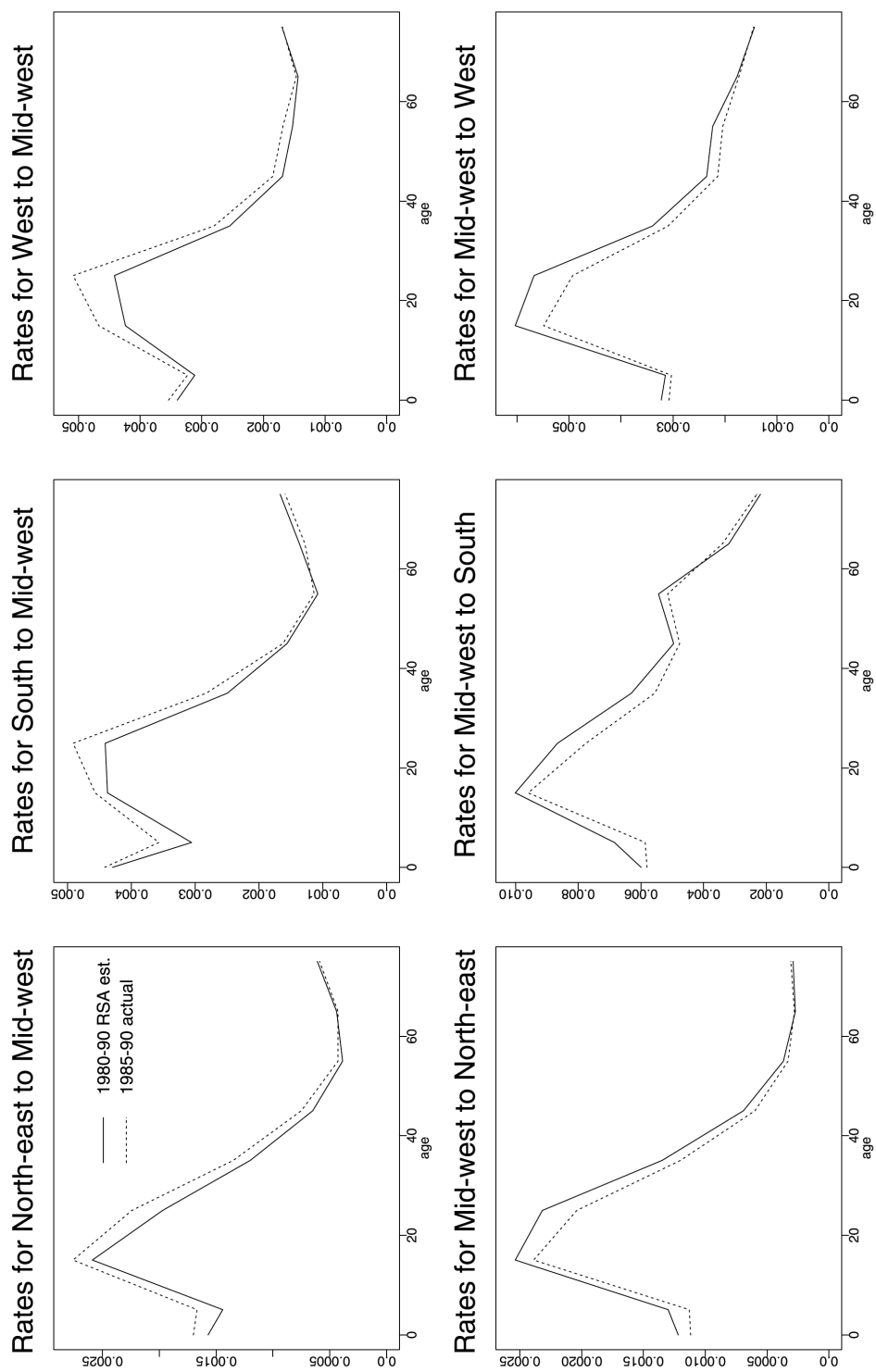

Figure 3: $\quad$ Interregional migration rates for females in the United States, 1985-1990 (actual) and 1980-1990 (RSA estimates) 
Table 5: $\quad$ Selected measures from multiregional life tables for United States females, 1980-90 (RSA and IPF estimates) and 1985-90 (actual)

\begin{tabular}{|c|c|c|c|c|c|c|c|c|c|}
\hline \multirow{4}{*}{$\begin{array}{l}\text { A. Number of Moves Per } \\
\text { Person }\end{array}$} & \multicolumn{3}{|c|}{ RSA 1980-90 } & \multicolumn{3}{|c|}{ IPF 1980-90 } & \multicolumn{3}{|c|}{$1985-90$} \\
\hline & \multicolumn{3}{|c|}{.676} & \multicolumn{3}{|c|}{.676} & \multicolumn{3}{|c|}{.674} \\
\hline & \multicolumn{3}{|c|}{ Entrants } & \multicolumn{3}{|c|}{ Exits } & \multicolumn{3}{|c|}{ Net Change } \\
\hline & \multicolumn{2}{|c|}{$1980-90$} & \multirow[t]{2}{*}{$1985-90$} & \multicolumn{2}{|c|}{$1980-90$} & \multirow[t]{2}{*}{$1985-90$} & \multicolumn{2}{|c|}{$1980-90$} & \multirow[t]{2}{*}{$1985-90$} \\
\hline B. Inter-Regional Moves & RSA & IPF & & RSA & IPF & & RSA & IPF & \\
\hline 1. North-east & 10,085 & 10,080 & 9,681 & 13,277 & 13,280 & 13,841 & $-3,192$ & $-3,200$ & $-4,160$ \\
\hline 2. Mid-west & 13,967 & 13,965 & 15,063 & 19,029 & 19,026 & 17,590 & $-5,062$ & $-5,061$ & $-2,527$ \\
\hline 3. South & 27,756 & 27,762 & 27,465 & 20,516 & 20,515 & 20,579 & 7,240 & 7,247 & 6,886 \\
\hline 4. West & 15,779 & 15,782 & 15,159 & 14,765 & 14,768 & 15,358 & 1,014 & 1,014 & -199 \\
\hline Total & 67,587 & 67,589 & 67,368 & 67,587 & 67,589 & 67,368 & 0 & 0 & 0 \\
\hline
\end{tabular}

Note: See Appendix B for calculation details

\section{Summary and conclusions}

We have developed, evaluated, and applied a new method, based on relative state attraction, that estimates interstate transfer rates from cross-sectional population distributions and an assumed set of standard rates. The RSA method performs as well as the leading alternative, iterative proportional fitting. Unlike IPF, however, RSA has a clear and plausible substantive interpretation and can be used to examine the implications of hypothesized changes in the power of attraction of different states.

A basic characteristic of the RSA method is that the product of the transfer rates between two states (i.e. the product $\mathrm{m}_{\mathrm{ij}} \mathrm{m}_{\mathrm{ji}}$ ) is the same in both the assumed standard and the resultant estimates. Hence, relative to the standard chosen, if the rates of transfer from one state (say i) to the other ( $\mathrm{j}$ ) increase, then the rates in the opposite direction are assumed to decrease. The effects of such constraints on the estimates were examined in the context of two-state and four-state models using stylized changes in the standard rates, and in a four state model where estimates were made based on rates observed in a nearby year. The results showed that RSA yields excellent estimates when there are large, compensating changes in interstate rates. When the rates between two states move in the same direction, the estimates are more in error, but nonetheless preserve the age pattern of behavior in the rates and generally yield age-aggregated summary measures close to actual levels.

A consistent feature of the evaluations was that RSA and IPF produced very similar estimates. Such a result was not expected, because the two methods are based on very different assumptions: RSA on changes in the attraction/repulsion of states that affect the risk of movement, and IPF on entropy maximization. That concordance of estimates is 
encouraging, however, because it suggests that one comes to a very similar result regardless of whether the problem is approached from a heuristic, more demographic, perspective or from the viewpoint of statistical estimation.

There are many circumstances where it is useful to estimate behavioral rates when only a standard pattern and two cross-sectional population distributions are known. The procedures developed here show how that can be done in a way that is easy to justify in nontechnical terms, that can be calculated in a straightforward fashion, and that gives results that typically approximate maximum likelihood estimates.

\section{Acknowledgements}

We gratefully acknowledge the assistance of William H. Frey in providing migration data for the United States, 1985-90, and thank Frans Willekens for his comments on an earlier draft. 


\section{Notes}

1. The present topic has tangential relationships to two other lines of research that are not pursued here. One is estimations from sequential cross sections in the decrement only context (see Schmertmann 2002). The other is estimating fertility and mortality from age distributions via inverse projection (cf. Lee 1985; Oeppen 1993).

2. There are many ways to go from population distribution (I) vectors to person-year $(\mathbf{L})$ vectors. The simplest is the linear assumption, used in the calculations presented here, where

$\mathbf{L}(\mathrm{t}, \mathrm{u})=(\mathrm{u} / 2)[\mathbf{l}(\mathrm{t})+\mathbf{l}(\mathrm{t}+\mathrm{u})]$

An alternative is to estimate the mean duration into the interval at which each type of transfer takes place, i.e. estimate the multistate version of Chiang's $a$. That can be done from a number of sources, including adjacent transfer rates (see Schoen 1988: Chapter 4 for a discussion of these and other techniques).

3. An anonymous reviewer has pointed out that published data on mortality and fertility may be available for each state. That would avoid the necessity of assuming unit $\mathrm{k}_{\mathrm{j}}(\mathrm{t}, \mathrm{u})$ factors for the dead and preborn states, and could well produce better values for the state-specific birth and death rates. To implement that idea, one could obtain statespecific birth and death rates for each age interval. The number of births and deaths in each state could then be calculated by multiplying those birth and death rates by the number of person-years lived in each state (i.e. the appropriate $\mathrm{L}_{\mathrm{j}}(\mathrm{t}, \mathrm{u})$ value). To insure that the system remains properly closed, at each age (i) the total end-of-interval population must be compared with (ii) the total beginning-of-interval population plus the total number of births minus the total number of deaths. Given data inconsistencies, it will probably be necessary to proportionately adjust all of the birth and death rates to make those two population figures equal. With mortality and fertility incorporated in this manner, the system is similar to the case with no mortality or fertility. Equation (4) can be solved for the $\mathrm{k}_{\mathrm{j}}(\mathrm{t}, \mathrm{u}) / \mathrm{k}_{\mathrm{i}}(\mathrm{t}, \mathrm{u})$ ratios (or one $\mathrm{k}_{\mathrm{j}}(\mathrm{t}, \mathrm{u}$ ) can arbitrarily be set equal to 1). Data limitations or inconsistencies may make this refinement unfeasible, and even when data are available the analyst must decide whether or not it is worthwhile. For the U.S. migration estimates (Figure 3 and Table 5), the refinement was not used because of concerns about data inconsistencies, the unavoidable errors introduced by the approximations needed to determine the number of persons born in each region, and the small effect of mortality at most ages. 


\section{References}

Batty, M. and S. Mackie. 1972. The calibration of gravity, entropy and related models of spatial interaction. Environment and Planning 4:205-33.

Bishop, Y.M., S.E. Fienberg, and P.W. Holland. 1975. Discrete Multivariate Analysis: Theory and Practice. Cambridge MA: MIT Press.

Chilton, R. and R. Poet. 1973. An entropy maximizing approach to the recovery of detailed migration patterns from aggregate census data. Environment and Planning 5:13546.

Deming, W.E. and F.E. Stephan. 1940. On a least squares adjustment of a sampled frequency table when the expected marginal totals are known. Annals of Mathematical Statistics 11:427-44.

Furness, K.P. 1965. Time function iteration. Traffic Engineering and Control 7:458-60.

Halli,S.S. and K.V. Rao. 1992. Advanced Techniques of Population Analysis. New York: Plenum.

Kruithof, J. 1937. Calculation of telephone traffic. De Ingenieur 52:E15-E25.

Lee, R.D. 1985. Inverse projection and back projection: A critical appraisal, and comparative results for England, 1539 to 1871. Population Studies 39:233-48.

McFarland, D.D. 1975. Models of marriage formation and fertility. Social Forces 54:66-83.

Moffitt, R. 1993. Identification and estimation of dynamic models with a time series of repeated cross-sections. Journal of Econometrics 59:99-123.

Moffitt, R. and M. Rendall. 1995. Cohort trends in the lifetime distribution of female family headship in the United States, 1968-1985. Demography 32:407-24.

Nair, P.S. 1985. Estimation of period-specific gross migration flows from limited data: Biproportional adjustment approach. Demography 22:133-42.

Oeppen, J. 1993. Back projection and inverse projection: Members of a wider class of constrained projection models. Population Studies 47:245-67.

Philipov, D. 1978. Migration and settlement in Bulgaria. Environment and Planning A 10:593-617.

Rogers, A., F. Willekens, and James Raymer. 2001. Modeling interregional migration flows: Continuity and change. Mathematical Population Studies 9:231-63. 
Ruggles, S. and M. Sobek et al. 1997. Integrated Public Use Microdata Series: Version 2.0. Minneapolis: Historical Census Projects, Univ. of Minnesota. (www.ipums.org).

Schoen, R. 1988. Modeling Multigroup Populations. New York: Plenum.

Schoen, R. and N. Standish. 2001. The retrenchment of marriage: Results from marital status life tables for the United States, 1995. Population and Development Review 27:553-63.

Schmertmann, C.P. 2002. A simple method for estimating age-specific rates from sequential cross sections. Demography 39:287-310.

U.S. National Center for Health Statistics. 1997. U.S.Decennial Life Tables for 1989-91, vol 1, no 1. Hyattsville MD.

Willekens, F. 1982. Multidimensional population analysis with incomplete data. Pp 43-111 in K.C. Land and A. Rogers (Eds), Multidimensional Mathematical Demography. New York: Academic Press.

Willekens, F. 1999. Modeling approaches to the indirect estimation of migration flows: From entropy to EM. Mathematical Population Studies 7:239-78. 


\section{APPENDIX A}

\section{Equations for the adjustment factors in a hierarchical two-state model}

1. A two-state hierarchical model can be described by the equations

$$
\begin{aligned}
& \mathrm{l}_{1}(\mathrm{t}+\mathrm{u})=\mathrm{l}_{1}(\mathrm{t})-\mathrm{L}_{1}(\mathrm{t}, \mathrm{u})\left[\mathrm{m}_{12}(\mathrm{t}, \mathrm{u}) \mathrm{k}_{2}(\mathrm{t}, \mathrm{u}) / \mathrm{k}_{1}(\mathrm{t}, \mathrm{u})+\mathrm{m}_{1 \delta}(\mathrm{t}, \mathrm{u}) / \mathrm{k}_{1}(\mathrm{t}, \mathrm{u})\right] \\
& \mathrm{l}_{2}(\mathrm{t}+\mathrm{u})=\mathrm{l}_{2}(\mathrm{t})-\mathrm{L}_{2}(\mathrm{t}, \mathrm{u}) \mathrm{m}_{2 \delta}(\mathrm{t}, \mathrm{u}) / \mathrm{k}_{2}(\mathrm{t}, \mathrm{u})+\mathrm{L}_{1}(\mathrm{t}, \mathrm{u}) \mathrm{m}_{12}(\mathrm{t}, \mathrm{u}) \mathrm{k}_{2}(\mathrm{t}, \mathrm{u}) / \mathrm{k}_{1}(\mathrm{t}, \mathrm{u})
\end{aligned}
$$

where $\delta$ indicates the dead state. There are transfers from state 1 to state 2 , but no births and no transfers from state 2 to state 1 . The solutions for $\mathrm{k}_{1}(\mathrm{t}, \mathrm{u})$ and $\mathrm{k}_{2}(\mathrm{t}, \mathrm{u})$ are

$$
\mathrm{k}_{2}(\mathrm{t}, \mathrm{u})=\left[\mathrm{l}_{1}(\mathrm{t}) \mathrm{k}_{1}(\mathrm{t}, \mathrm{u})-\mathrm{l}_{1}(\mathrm{t}+\mathrm{u}) \mathrm{k}_{1}(\mathrm{t}, \mathrm{u})-\mathrm{L}_{1}(\mathrm{t}, \mathrm{u}) \mathrm{m}_{1 \delta}(\mathrm{t}, \mathrm{u})\right] /\left[\mathrm{L}_{1}(\mathrm{t}, \mathrm{u}) \mathrm{m}_{12}(\mathrm{t}, \mathrm{u})\right]
$$

where $\mathrm{k}_{1}(\mathrm{t}, \mathrm{u})$ is the positive root of the quadratic equation

$$
\begin{aligned}
0 & =\left[\mathrm{k}_{1}(\mathrm{t}, \mathrm{u})\right]^{2}\left\{\left[\mathrm{l}_{1}(\mathrm{t})-\mathrm{l}_{1}(\mathrm{t}+\mathrm{u})\right]^{2}+\left[\mathrm{l}_{1}(\mathrm{t})-\mathrm{l}_{1}(\mathrm{t}+\mathrm{u})\right]\left[\mathrm{l}_{2}(\mathrm{t})-\mathrm{l}_{2}(\mathrm{t}+\mathrm{u})\right]\right\} \\
& +\mathrm{k}_{1}(\mathrm{t}, \mathrm{u}) \mathrm{L}_{1}(\mathrm{t}, \mathrm{u})\left\{\mathrm{m}_{1 \delta}(\mathrm{t}, \mathrm{u})\left[2 \mathrm{l}_{1}(\mathrm{t}+\mathrm{u})-2 \mathrm{l}_{1}(\mathrm{t})+\mathrm{l}_{2}(\mathrm{t}+\mathrm{u})-\mathrm{l}_{2}(\mathrm{t})\right]-\mathrm{L}_{2}(\mathrm{t}, \mathrm{u}) \mathrm{m}_{2 \delta}(\mathrm{t}, \mathrm{u}) \mathrm{m}_{12}(\mathrm{t}, \mathrm{u})\right\} \\
& +\left[\mathrm{L}_{1}(\mathrm{t}, \mathrm{u}) \mathrm{m}_{1 \delta}(\mathrm{t}, \mathrm{u})\right]^{2}
\end{aligned}
$$

2. A two-state non-hierarchical model with no fertility or mortality can be described by the equations

$$
\begin{aligned}
& \mathrm{l}_{1}(\mathrm{t}+\mathrm{u})=\mathrm{l}_{1}(\mathrm{t})-\mathrm{ZL}_{1}(\mathrm{t}, \mathrm{u}) \mathrm{m}_{12}(\mathrm{t}, \mathrm{u})+\mathrm{L}_{2}(\mathrm{t}, \mathrm{u}) \mathrm{m}_{21}(\mathrm{t}, \mathrm{u}) / \mathrm{Z} \\
& \mathrm{l}_{2}(\mathrm{t}+\mathrm{u})=\mathrm{l}_{2}(\mathrm{t})-\mathrm{L}_{2}(\mathrm{t}, \mathrm{u}) \mathrm{m}_{21}(\mathrm{t}, \mathrm{u}) / \mathrm{Z}+\mathrm{Z} \mathrm{L}_{1}(\mathrm{t}, \mathrm{u}) \mathrm{m}_{12}(\mathrm{t}, \mathrm{u})
\end{aligned}
$$

where $\mathrm{Z}=\mathrm{k}_{2}(\mathrm{t}, \mathrm{u}) / \mathrm{k}_{1}(\mathrm{t}, \mathrm{u})$. Using the first equation in (A.4) and solving the quadratic yields

$$
\begin{aligned}
& \mathrm{Z}=\left[1 /\left(2 \mathrm{~L}_{1}(\mathrm{t}, \mathrm{u}) \mathrm{m}_{12}(\mathrm{t}, \mathrm{u})\right)\right]\left[\left\{\mathrm{l}_{1}(\mathrm{t})-\mathrm{l}_{1}(\mathrm{t}+\mathrm{u})\right\} \pm\left[\left\{\mathrm{l}_{1}(\mathrm{t})-\mathrm{l}_{1}(\mathrm{t}+\mathrm{u})\right\}^{2}\right.\right. \\
& \left.\left.+4 \mathrm{~L}_{1}(\mathrm{t}, \mathrm{u}) \mathrm{m}_{12}(\mathrm{t}, \mathrm{u}) \mathrm{L}_{2}(\mathrm{t}, \mathrm{u}) \mathrm{m}_{21}(\mathrm{t}, \mathrm{u})\right]^{1 / 2}\right]
\end{aligned}
$$

From (A.5), it is evident that the positive root always yields a realistic (i.e. positive) value for $\mathrm{Z}=\mathrm{k}_{2}(\mathrm{t}, \mathrm{u}) / \mathrm{k}_{1}(\mathrm{t}, \mathrm{u})$, while the negative root always yields a negative value for $\mathrm{Z}$, because the expression whose square root is taken must be positive and greater than the square of $\left[\left\{l_{1}(t)-1_{1}(t+u)\right\}\right.$. 


\section{APPENDIX B}

\section{Calculating multiregional life tables for the United States, 1980-90}

The population data for the calculations were obtained from the Integrated Public Use Microdata Series (IPUMS, available at www.ipums.org/usa/doc.html; see Ruggles and Sobek et al 1997). From the 1980 and 1990 census public use microdata 5\% samples, information was extracted on the age, sex, state of residence, state of birth (only U.S. born persons were included), person sampling weight, and (for 1990) state of residence in 1985. States were aggregated into 4 regions: North-east (Connecticut, Maine, Massachusetts, New Hampshire, New Jersey, New York, Pennsylvania, Rhode Island, and Vermont), Midwest (Illinois, Indiana, Iowa, Kansas, Michigan, Minnesota, Missouri, Nebraska, North Dakota, Ohio, South Dakota, and Wisconsin), West (Alaska, Arizona, California, Colorado, Hawaii, Idaho, Montana, Nevada, New Mexico, Oregon, Utah, Washington, Wyoming), and South (the remaining states and the District of Columbia). Throughout, mortality in all regions was assumed to follow that of the U.S Life Tables for 1989-91 (U.S. National Center for Health Statistics 1997).

To prepare the multiregional life tables for 1985-90, the male and female populations were each put in 5-year age groups for ages 0-4 through 80-84 years, with ages 85 and over combined. The calculation procedure followed was essentially that described in Schoen (1988:76-79). For ages 5-9 through 80-84, retrospective proportions $\mathrm{R}_{\mathrm{ij}}$ were calculated as the ratio of (a) the number in state $i$ in 1985 who were in state $j$ in 1990 to (b) the sum over all regions $\mathrm{j}$ of those who were in state $\mathrm{i}$ in 1985 and in state $\mathrm{j}$ in 1990. Survivorship proportions $S_{\mathrm{ij}}$ were calculated from the $\mathrm{R}_{\mathrm{ij}}$ by back surviving the total 1990 population to 1985, using the 1989-91 U.S. female life table. Migration at ages over 85 was assumed to be the same as at ages 80-84. State of birth was used as the previous state for persons aged 0-4 in 1990. Elements of the Markov transition probability matrices (П) were then found as the arithmetic mean of the $S_{i j}$ for that and the preceding age interval. The (i,j) element of $\boldsymbol{\Pi}$ is the probability that a person in state $j$ at the beginning of an interval is in state $i$ at the end of the interval. The matrix of interstate transfer rates was then obtained by the linear relationship $\mathbf{M}=(2 / 5)[\mathbf{I}+\boldsymbol{\Pi}]^{-1}[\mathbf{I}-\boldsymbol{\Pi}]$, where $\mathbf{I}$ represents the identity matrix. The life table was calculated using a program very similar to Program IDLT in Schoen (1988:Appendix D), but with linear survivorship. The initial number of persons in each state was allocated in proportion to the reported state of birth of persons under 5 in the 1990 Census.

For the 1980-90 life tables, the 1990 population was accepted as reported. Because of inconsistencies between the 1980 and 1990 age-sex distributions, it was necessary to estimate the total 1980 U.S. born population by back surviving the 1990 population using the 1989-91 U.S. life tables. Within each age-sex group, that number was allocated to 
regions in the same proportion as found in the 1980 Census data. Ten year age groups were used from ages 5-14 through 75-84 for consistency with the 10 year time interval. (The 5year of age rates for 1985-1990 were aggregated to 10 year rates by multiplying consecutive 5-year $\Pi$ matrices, and then transforming the products to rate matrices.) For the RSA rates, a variant of equation (4) was used to find the adjustment factors, with the 1985-90 rates taken as the standard. With that same standard, the IPF rates were calculated by programming the iterative procedure described in the text. Program IDLT, with modified age categories and linear survivorship, was used to construct the 1980-90 multiregional life tables. The initial number of persons in each state reflects the reported state of birth of persons aged 5-9 in the 1990 Census. The summary measures were found by summing the number of interregional moves in each life table population. 